\title{
Are all complainants of sexual assault vulnerable? Views of Australian criminal justice professionals on the evidence-sharing process
}

\author{
Sarah L. Deck \\ Centre for Investigative Interviewing, Griffith Criminology Institute, Griffith University, \\ Australia. ORCID ID: 0000-0001-9213-0352 \\ s.deck@griffith.edu.au \\ Martine B. Powell \\ Centre for Investigative Interviewing, Griffith Criminology Institute, Griffith University, \\ Australia. ORCID ID: 0000-0001-5092-1308 \\ martine.powell@griffith.edu.au \\ Jane Goodman-Delahunty \\ Newcastle Law School, University of Newcastle, Australia ORCID ID: 0000-0003-4409- \\ 0063.jane.delahunty@newcastle.edu.au
}

Nina Westera ${ }^{1}$

Griffith Criminology Institute, Griffith University, Australia

\section{Corresponding author:}

Martine Powell

Email: martine.powell@griffith.edu.au

Griffith Criminology Institute

176 Messines Ridge Road

Mt Gravatt Queensland 4122

Australia

\footnotetext{
${ }^{1}$ Deceased 25 May 2017
} 


\section{Acknowledgements:}

Preparation of this article was funded in part by a grant 'An Evaluation of How Evidence is Elicited from Complainants of Child Sexual Abuse' from the Australian Royal Commission into Institutional Responses to Child Sexual Abuse. Views and findings expressed in this report are those of the authors and do not necessarily reflect those of the Royal Commission. 


\begin{abstract}
Cases of historic child assault typically rely on the complainant's narrative due to lack of corroborating evidence. Although it is important that complainants give their best evidence, concern has been expressed that evidence-sharing procedures are suboptimal. This study explored criminal justice professionals' perspectives on the utility of introducing reforms to the evidence-sharing process. We interviewed judges, prosecutors, defence counsel, and witness assistance officers $(N=43)$ on the utility of regulating the questioning of complainants and of using videorecorded interviews as evidence-in-chief. Many professionals perceived that adult complainants of child assault were vulnerable and supported reforms to evidence-sharing. Primary objections to these reforms were the belief that all adult complainants should share evidence in the same way and the poor quality of investigative interviews. This study illuminates potential barriers to the implementation of reforms which would change how adult complainants of child assault give evidence.
\end{abstract}

Keywords: Child sexual assault, Vulnerable, Special measures, Complainant evidence, Memory 


\section{INTRODUCTION}

Delayed reporting of child sexual assault is common, with many people disclosing their experience for the first time in adulthood (Allagia et al., 2019). Yet the prosecution of historic child sexual assault presents a unique challenge to the legal system. Many cases are never reported, and of those that are, there are high rates of attrition and low rates of prosecution (Daly and Bouhours, 2010; Fitzgerald, 2006). In cases involving sexual offences, there is typically a reliance on the alleged victim's narrative, due to lack of supporting evidence (Shead, 2014). Although it is important that complainants give their best evidence, both scholars and the media have expressed concern that evidence-sharing procedures in sexual assault trials are far from optimal (e.g., Kinsella, 2021; Zajac and Cannan, 2009). In this study, we explored Australian criminal justice professionals' perspectives on how adult complainants of child sexual assault share evidence in court, and the utility of legislative reforms.

Contextual factors compound the challenge in giving historical evidence. Although victims react to traumatic events in various ways, child sexual assault a risk factor for short and longterm psychological and cognitive impairment (see Cashmore and Shackel, 2013; De Bellis and Zisk, 2014 for a review). For example, individuals exposed to child sexual assault tend to perform more poorly on measures of language ability (Lum et al.,2015), and are more likely to experience ongoing psychological challenges, including mood, anxiety, and substance use disorders, than individuals with no history of child sexual assault (Cutajar et al, 2010; Hong et al., 2018; Li et al., 2020; Maniglio et al., 2013). The risk of these negative psychological and cognitive outcomes is more pronounced when the assault was ongoing, or when other forms of abuse (e.g., physical and/or emotional abuse) were also experienced (Holt et al., 2007; Jaffee and Maikovich-Fong, 2011) The vulnerability of complainants is heightened in the 
context of the sexual assault trial, where complainants are expected to share explicit details about the sexual violence committed against them (New South Wales Law Reform Commission [NSWLRC], 2003). The difficulty of this task is enhanced by the complicated relationship the victim has with the accused, who is commonly a member of their own family (NSWLRC, 2003; Quadara et al., 2015). Sexual offence trials place additional stress upon the complainant due the inevitable focus upon the complainant's credibility (NSWLRC, 2003; Shead, 2014). Because the complainant often provides the primary evidence in sexual offence trials, the defence typically adopts a theory of case which challenges the complainant's credibility, resulting in cross-examination that is distinctly personal (NSWLRC, 2020). For these reasons, giving evidence is particularly distressing for complainants of sexual assault, as compared to complainants in other criminal proceedings (NSWLRC, 2003; Queensland Law Reform Commission [QLRC], 2020). Such high levels of stress during the trial are likely to impede the complainants' ability to recall episodic memories of assault (Wolf, 2017). Thus, although victims of child sexual assault can reliably recall traumatic events decades afterwards (Goldfarb et al., 2020), high levels of stress at trial are likely to adversely impact the complainants' ability to provide best-quality evidence.

Adult complainant of sexual assault can be described as vulnerable. We define a vulnerable witness as an individual who is likely to have difficulty sharing (i.e., giving) evidence in accordance with standard adversarial trial procedures and is at particular risk of misunderstanding and miscommunication. In recognition of these challenges, a number of international jurisdictions have amended the procedures by which adult complainants of sexual assault are expected to share evidence (For example, see Evidence Act 2006 (NZ) s 103; Youth Justice and Criminal Evidence Act 1999 (UK) ss 16-33). In most Australian jurisdictions, however, adult complainants of sexual offences are required to give evidence in 
accordance with standard proceedings. The current study considers how adult complainants of delayed child assault prosecutions give evidence, and whether legislative reform should be introduced to assist complainants. Specifically, we asked criminal justice professionals about their perspective on the utility of introducing additional restrictions to the scope of questioning, and permitting complainants to use pre-recorded interviews as evidence-in-chief.

\section{A. Questioning Practices in Court}

Concern about questioning practices in court has mostly centred on cross-examination, a process which purportedly aims test the credibility and accuracy of the evidence given by an appointed court witness (Ellison, 1999). In practice, the aggression of the practices utilised during cross-examination have led some scholars to question whether they constitute 'legitimated bullying' (Henning, 2006). Analyses of transcripts from adult sexual assault trials have shown that cross-examining lawyers commonly use questions which imply that the complainant is lying and invoke rape myths to discredit their evidence (e.g., questioning why the complainant delayed reporting), which is highly distressing for complainants (Horan and Goodman-Delahunty, 2020; NSWLRC, 2020; Zajac and Cannan, 2009; Zydervelt et al., 2017). Moreover, lawyers typically adopt a questioning style which is likely to confuse the witness and impair the accuracy of their responses. Analysis of court transcripts indicate that it is routine practice for cross-examining lawyers to ask adult sexual assault complainants questions that are leading, constrain the witness to a yes/no response, and are confusing (e.g., asking multiple questions which require different answers in succession; Kebbell et al., 2003; Westera et al., 2017). These questioning practices contrast to best-practice interview principles which encourage the use of open-ended non-leading questions (see, Lamb et al., 2018, for a review). Although adults are affected to a lesser extent than children, a robust body of research indicates that the accuracy of adults' responses are affected by questiontype, with leading questions impairing accuracy relative to non-leading, open-ended 
questions (e.g., Roebers and Schneider, 2000). Indeed, adult witnesses often make changes to their evidence during these cross-examination style questions (Valentine and Maras, 2011; Westera et al., 2017; Zajac and Cannan, 2009). In addition to impairing accuracy, crossexamination is the most distressing part of evidence-sharing for adult sexual assault complainants (Kebbell, O’Kelly and Gilchrist, 2007; Konradi, 1999). Prior to considering whether legislation should be introduced to place limitations on the scope and nature of crossexamination of adult sexual assault complainants, it is helpful to obtain the perspectives of criminal justice professionals on the utility of this reform.

\section{B Using Pre-Recorded Interviews as Evidence}

To assist vulnerable witnesses giving evidence, a number of jurisdictions have introduced special measures, which permit deviations from standard evidence-sharing procedures. Indeed, jurisdictions in New Zealand (Evidence Act 2006 (NZ) s 103) and the United Kingdom (Youth Justice and Criminal Evidence Act 1999 (UK) s 17) now permit the use of videorecorded police interviews as evidence-in-chief in adult sexual offence trials. Although children and individuals with a cognitive impairment are generally considered eligible for special measures in Australian jurisdictions (see, Royal Commission into Institutional Responses to Child Sexual Abuse, 2017, for a review), most do not permit the use of prerecorded evidence for adult sexual assault complainants, with the exception of the Northern Territory (Evidence Act 2011 (NT) s 21B) and Tasmania (Evidence (Children and Special Witnesses) Act 2001 (Tas) s 8(2)). The potential benefits of using videorecorded evidence are two-fold. First, using special measures may improve the willingness of witnesses to give evidence (McDonald and Tinsley, 2011). In a survey of alleged victims of sexual offences in the UK, $44 \%$ of adult respondents indicated that they would not have given evidence without special measures (Hamlyn et al., 2004). In another survey of women who had given evidence in rape trials, nearly $80 \%$ of respondents were supportive of the special measure of video- 
recorded police interviews as evidence (Kebbell, O'Kelly and Gilchrist, 2007). Second, using pre-recorded interviews as evidence has the potential to improve the quality of testimonial evidence given by witnesses. During evidence-in-chief, adult sexual assault complainants are typically asked a high proportion of leading and closed questions, which are likely to impede accuracy and restrict the detail in their responses (Kebbell et al., 2003). This practice is contrary to the principle that questions are not meant to be leading during the direct examination or re-examination of a witness (e.g., Australian Law Reform Commission [ALRC], NSWLRC, Victorian Law Reform Commission [VLRC], 2006). Non-leading openquestions elicit more detailed, accurate, and coherent responses than specific questions (Feltis et al., 2010; Lamb et al., 2018). The more relaxed setting of the interview room is additionally likely to facilitate retrieval and increase the likelihood that witnesses will feel comfortable disclosing intimate details (e.g., whether penetration occurred) which are often crucial to establishing the elements of the offence (Westera et al., 2012; Wolf, 2017).

Two prior investigations explored criminal justice professionals' perspective on the utility of pre-recorded interviews as evidence for adult sexual assault complainants, in a sample of New Zealand prosecutors (Westera et al., 2017) and a mixed sample of prosecutors from New Zealand and Australia (Westera and Powell, 2015). Although most prosecutors were supportive of pre-recorded interviews as evidence, there were a number of barriers preventing their effectiveness, including poor quality police interviews and concern about the perceived credibility of complainants on film. Prosecutors' responses in these studies indicated that the utility of this measure may be different for cases of historic child assault, as certain advantages (e.g., capturing memory reports prior to decay) did not apply. Prosecutors additionally expressed that a major barrier to the implementation of special measures in practice was reluctance by other key stakeholders, including defence counsel and judges 
(Westera and Powell, 2015). Given that lack of stakeholder support can prevent the use of special measures once they are permitted following legislative reform, it is important to explore the perspective of a variety of stakeholders on the utility of video-recorded evidence.

The purpose of this study was to investigate stakeholders' perceptions of current evidencesharing practice in delayed prosecutions of child sexual assault involving adult complainants, as well as the utility of potential reforms. Specifically, we explored perspectives of a representative sample of Australian criminal justice professionals: judges, defence counsel, prosecution lawyers and witness assistants on the usefulness of introducing restrictions to cross-examination and of permitting pre-recorded interviews as evidence-in-chief for adult complainants.

\section{METHOD}

\section{A Participants}

Recruitment of criminal justice professionals occurred across four Australian jurisdictions (New South Wales, Victoria, Western Australia, and Tasmania) via offices of public prosecution, law firms conducting criminal defence work, a barristers' society, members of the judiciary, and witness support agencies (which support witnesses throughout the court process). Witness assistants from public support agencies typically support witnesses by familiarising them with the trial process, updating them on the progress of the case, and debriefing them after the trial. Potential participants were identified in one of two ways, according to the preferences of the organisations. The agency either nominated eligible professionals or circulated an email requesting volunteer participants. Initially, 58 eligible criminal justice professionals were identified and approached, of whom 43 consented to participate. All were experienced in their professional role (see Table 1 for participant characteristics) 
Insert Table 1 around here

\section{B Procedure}

Participants were either interviewed over the phone $(n=34)$ or in-person $(n=9)$. During the interview, they were asked to reflect on how complainants are questioned in court, and the special measure of a pre-recorded investigative interview as evidence-in-chief. For each topic, participants were asked to reflect on current practice, policy and process in their jurisdiction, the reasons for any variations in practice, the strengths and limitations of current practice, and whether the process could be improved. Although participants were asked to reflect on these questions for both child and adult complainants, their responses regarding child complainants have been reported elsewhere (Westera et al., 2020; Westera et al., 2019). This paper addresses responses unique to adult complainants of sexual assault. Due to the exploratory nature of this research, broad open-ended questions were asked to encourage detailed responses. Responses were analysed inductively using a bottom-up approach, instead of relying upon existing conceptual frameworks (Strauss and Corbin, 1990). After these key topics had been discussed, participants were asked how long they had worked in their profession. Interviews were audio-recorded, transcribed verbatim, double-checked for accuracy, and de-identified.

\section{Analysis}

Initially, two primary researchers independently coded the transcripts by performing a lineby-line analysis (reduction) of the transcripts and identifying concepts within statements. Statements that embodied similar concepts were grouped together. The primary researchers met to discuss concepts they had individually identified; there was a high rate of agreement 
between them. The transcripts were subsequently re-analysed to identify quotes that supported the identified categories, and the quotes were categorised according to core themes. Once the primary researchers had reached consensus on all themes, an additional researcher re-analysed the transcripts by theme and extracted quotes which were illustrative of them. The quotes were altered to de-identify participants and correct minor grammatical errors.

\section{RESULTS}

The two main themes that arose when participants discussed lawyers' questioning were that cross-examination is aggressive and demeaning, and that adults should be tested robustly. When considering the use of pre-recorded interviews as evidence-in-chief, the four main themes that emerged were that all complainants of sexual assault are vulnerable, that adults should not receive special measures, the poor quality of police interviews, and the reliability and credibility of the complainant. These themes are described in greater detail below.

\section{A Regulating the Questioning of the Complainant}

Participants had mixed views as to whether reforms should be introduced to regulate the questioning of adult complainants. Of our sample, $41 \%$ felt that current questioning was working effectively; $33 \%$ stated that effectiveness varied depending on the circumstances and $26 \%$ indicated that it was ineffective. Two primary themes emerged in the interviews, both of which centred on cross-examination.

Many participants expressed concern about cross-examination practice, which they described as insulting and humiliating to complainants. One defence counsel commented that an aggressive cross-examination style was more common in cases of historical (compared to more recent) sexual assault. Although participants from each profession were not satisfied with how cross-examination was conducted, witness assistants were particularly passionate in describing how difficult and distressing the experience of cross-examination was for 
complainants. In voicing their concern about cross-examination practice, many participants expressed the view that all complainants of sexual assault were vulnerable, irrespective of age, and that adult complainants needed more protection. Although several prosecutors noted that there is some protection for complainants under the Evidence Act, they commented that there is considerable leeway for interpretation the Act, and that complainants are still frequently being questioned in a manner which is unfair and oppressive. Several lawyers also noted that although cross-examination can be belittling, there is variability in how it is conducted, stating that some defence lawyers cross-examine fairly and effectively.

Cross-examination re-traumatises complainants. Some people get quite angry. Some people get highly distressed. We actually have vomit bags because people get so distressed that they vomit. So that vigorous, relentless sort of cross-examination causes a lot of distress. (Witness assistant)

All victims of sexual assault are vulnerable in the witness box...vulnerable to suggestion, being insulted, humiliated, and worn down. Comments regarding crossexamination of children apply equally to adults. (Prosecutor)

I would not want to be a complainant. It is a strange situation to be in because victims also have the presumption of innocence during the trial, and if these victims are genuine victims, then they are spoken to in a way that they should not be spoken to. (Defence Lawyer)

We still need to protect adults from inappropriate cross-examination. (Judge)

In contrast to the view that all complainants of sexual assault are vulnerable, other participants stated that vigorous questioning should be permitted. These participants often referred to the emotional and cognitive maturity of adults relative to children, and reasoned that adults could withstand robust questioning, especially when given adequate pre-trial preparation. Several judges and prosecutors additionally commented that vigorous crossexamination was necessary to protect the rights of the accused. To enable the evidence to be adequately tested, these participants were content for cross-examination of adults to continue without additional restrictions. One prosecutor stated that this rigorous testing of the evidence was especially important in cases of historical sexual assault. Two judges also expressed 
satisfaction with how cross-examination was conducted with adults, noting that the vigour of questioning has improved considerably over the course of their careers.

I do not see the need for open-ended questions in cross-examination for adults, and even older children, because they are capable linguistically, and during the preparation for court, the support services and prosecutor can tell them they have to pay attention and be careful about how they answer questions. (Prosecutor)

You have a bit more latitude in what you can ask and the approach you can take when you are dealing with an adult. They are assumed to have a higher degree of emotional robustness and maturity. (Defence)

Adults are obviously going to be subject to more vigorous cross-examination. But it has to be a discretionary matter, because the case may require it, so cross-examination is appropriate. It could lead to unfair trials if there was some blanket statement or legislation prohibiting vigorous cross-examination. (Judge)

\section{B Using Pre-recorded Investigative Interviews}

Participants were divided in their support for giving adult sexual assault complainants the option to use pre-recorded investigative interviews as evidence-in-chief. Overall, $36 \%$ supported the reform, $22 \%$ indicated support depending on the circumstances, and $42 \%$ did not support it.

Many participants indicated that using pre-recorded interviews would greatly reduce the amount of stress complainants experienced. Participants who supported the reform perceived all complainants of sexual assault as vulnerable witnesses and stated that it was unfair to have an arbitrary age at which this special measure was no longer an option. Witness assistants were particularly supportive of this reform, describing the additional anxiety that complainants experienced as they attempted to remember their statement over long time periods leading up to the trial.

I'm supportive of videotaped evidence for adults. Adults are not that different from children, they are still feeling the same things, the anxiety, the nerves, and the length of time between the report and trial obviously affects their memory as well. Then being up there and getting asked all those intimate details. (Witness assistant) 
Using police interviews as evidence-in-chief would be good, for the same reasons it is for a child. We are talking about adults that have been extremely vulnerable because of the crime that has been committed against them. (Prosecutor)

Why can't all vulnerable witnesses give their evidence by a recorded interview? With the definition of vulnerable being one of the proscribed sexual offences. (Witness assistant)

Conversely, other participants expressed that all adult complainants should receive the same treatment, and that evidence-sharing options should not differ according to the type of offence alleged. Participants indicated that child complainants are entitled to the option of using pre-recorded interviews as evidence because of their developmental immaturity. They commented that this justification does not apply to adults, who are more cognitively advanced and emotionally robust than children. One defence lawyer additionally commented that it would be unfair to the accused if adult complainants could use a video-recorded interview as evidence.

Once you are an adult you have to be treated as an adult and give evidence in court. They should have to elect to give evidence, and by all means use a remote witness room, but they need to be dealt with like any other witness in any other court case. (Judge)

I do not necessarily see any reason for singling out adult complainants of sexual assault as compared to adult complainants of a physical assault or kidnapping or any other particular crime. The rationale for recorded interviews is not there as it is for children. (Defence Lawyer)

We can all agree that children have to have special rules that apply to them, but it is fair to expect that adults should be required to deal with the stress of examination-inchief. (Defence Lawyer)

Participants indicated that the utility of using police interviews as evidence was dependent upon the competency of the interviewer. Many expressed strong dissatisfaction with police interviewing practice, stating that the low quality of police interviews prevented them from being useful evidence in court. Although many acknowledged that interviewing alleged victims of sexual assault requires a high degree of skill, they did not perceive police as 
sufficiently qualified to conduct these interviews. Participants were particularly concerned about the tendency of police to focus on unnecessary extraneous details. These extraneous details could be used to damage complainant credibility by highlighting or eliciting inconsistencies during cross-examination. Participants commented that the defence would be more likely to target these inconsistencies if the complainant were an adult rather than a child. Several participants were particularly concerned about using police interviews in trials involving historical sexual assault, as complainants often provided a vague and confused narrative because they had experienced assault repeatedly. Several participants also commented on the conflicting requirements of police investigations and evidential processes, noting that police interviews are tailored to address the former.

God! I dread the day that pre-recorded police interviews for adults would be inflicted upon us. It would not help anyone other than the defence. All those interviews do, by drilling down into colours of lunchboxes, is open up an excess of detail that the defence can cross-examine on. I would be sad to see that happen. (Defence Lawyer)

The interviewing officer needs to be very good at what they do. You do not want a lot of extraneous material that is irrelevant in the interview, because that can cast a shadow over the really good evidence. (Prosecutor)

If adults gave their evidence by visually recorded interview a long time before trial, they would be cross-examined on any inconsistencies. That does not happen that much with children because it is just too hard, unless there are obvious material inconsistencies. But, if you were dealing with adults, that could occur more. (Judge)

I would not advocate using the recorded police interview for adults, because there is this tension between the investigative and evidence producing process. If they are able to give an account in court, which is focused on the issues, so it is evidence producing questioning rather than investigative questioning, then it is likely to be more condensed and generally more impressive before the jury. The preliminary interviews are an advantage for children, but I am not convinced we ought to adopt the process for adults. (Judge)

Irrespective of the quality of the initial interview, however, the participants had mixed views as to whether pre-recorded interviews would be beneficial. Several perceived video interviews as compelling evidence due to the complainant's obvious distress when they articulated their account for the first time, and the spontaneity of their responses. Conversely, 
one prosecutor suggested that pre-recorded interviews were less compelling than a live account before the court. Participants also considered whether pre-recorded interviews would have a positive impact on the reliability of the complainant's narrative. Many of these comments were positive. Participants suggested that that the memory of complainants is fresher and less likely to be contaminated by external influences when their evidence is given via a pre-recorded interview rather than in court after lengthy delays. Conversely, other participants indicated that adults should be able to remember their statement over long periods of time without substantial memory decay. Several participants also noted that video recorded interviews confer no benefit to complainant reliability when child sexual assault is alleged, as the benefit of capturing a fresh account was lost.

The initial video-recorded complaint can be incredibly compelling because of the way that it is said and the obvious distress...This could be very important because those trials always inevitably focus on the credibility of the complainant. (Prosecutor)

There are two great advantages; one is that the evidence is there, so later down the track you do not have a problem if the complainant is frightened and decides they do not want to come and give evidence. The second is that the jury get to see the complainant's response when they first go to the police, instead of years down the track, and their first disclosure can be very compelling in how they answer questions. It is much more artificial in court. (Prosecutor)

For cases where the offences occurred 30/40 years ago, it would not really help doing a pre-recorded interview as opposed to giving evidence live at trial. (Prosecutor)

\section{DiSCUSSION}

Many participants expressed the view that all complainants of child sexual assault should be considered vulnerable. These participants were supportive of reforms to the evidence-sharing process, expressing concern about the aggression of cross-examination and supporting the use of pre-recorded interviews as evidence. Conversely, participants who were not supportive of these reforms often commented that all adult complainants should receive the same treatment. Next, we consider stakeholder's main objections to introducing legislative reforms to the evidence-sharing process in greater detail. 
A primary objection to introducing reforms was that complainants of sexual assault are not distinct from adult complainants of any other offence. Participants who held this perspective often commented that adult complainants of sexual assault were emotionally and cognitively mature and should thus be expected to give evidence in accordance with standard procedures. The claim that complainants of sexual assault are similar to all other adult complainants is contrary to the unique progression of sexual offence cases through the criminal justice system, with low reporting, high attrition, and low prosecutions rates relative to non-sexual offences (Daly and Bouhours, 2010; Fitzgerald, 2006; NSWLRC, 2020). These problems are heightened for cases of historical child assault by adult complainants (Fitzgerald, 2006). A principal factor likely to contribute to these outcomes is the unique characteristics of victims of child assault, who are more likely to experience psychological and cognitive challenges than the general population (Hong et al., 2018; Li et al., 2020; Maniglio et al., 2013). Moreover, at trial, complainants are expected to share sensitive details about a traumatic childhood event in front of the alleged offender. Victims of assault often have complex relational dynamics with the offender for a variety reasons, including the grooming and intimidation they were subjected to as a child (Shead, 2014). Thus, for complainants who are genuinely retelling their experience, the evidence-sharing process is likely to elicit high levels of distress (Konradi, 1999). Indeed, stakeholders often emphasized how distressing the evidence-sharing process was. These participants also highlighted the additional stress that complainants experienced as they attempted to remember their statement after long delays leading to the trial. Using videorecorded interviews is likely to alleviate the stress complainants experience in the period leading up to trial, and the evidence-sharing process itself.

When expressing the view that all adult complainants should give evidence in the same way, some participants expressed concern that it would be unfair to the accused if the scope of 
cross-examination were restricted. Although the right to a fair trial has traditionally focused upon the needs of the defendant, in recent times it has been acknowledged that a fair trial involves a triangulation of interests between the complainant, the accused, and the public (Attorney-General's Reference (No. 3 of 1999) [2001] 2 AC 91 [118], Ragg v Magistrates Court of Victoria (2008) 18 VR 300; $R$ v Wilkie (2005) 193 FLR 291; Victorian Law Reform Commission [VLRC], 2016). Discussions about restrictions to the scope of cross-examination are often conceptualised as a balancing act between these various interests (e.g., Australian Law Reform Commission, NSWLRC, VLRC, 2006). Underlying this metaphor is the assumption that improper questions protect the rights of the accused, but these rights must be weighed against the rights of witnesses and the public. This assumption is flawed (Henning, 2006). Cross-examination questions which undermine the reliability of evidence, threaten the legitimacy of trial determinations, which is contrary to the interests of the accused, the complainant, and the public (Henning, 2006). We acknowledge that cross-examination is a fundamental component of a fair trial. It enables a test of the evidence which protects the rights of the accused (e.g., VLRC, 2016). Cross-examination may indeed illuminate the credibility and reliability of a witness' evidence (Mechanical Inventions v Austin [1935] AC 346, 359). However it does not achieve this purpose when the questions posed contaminate the witness' evidence (e.g., through leading or repetitive questions; Kebbell et al, 2003; Westera et al., 2017). In our study, participants expressed optimism that the needs of the accused and the alleged victim could both be met when cross-examination is conducted in a fair and effective manner. To protect the interests of the complainant, the accused, and the public, improper questions must not be asked.

Participants expressed that judges were often reluctant to intervene during cross-examination. Analyses of transcripts of sexual assault trials confirmed that judicial intervention is rare 
(e.g., Cashmore and Trimboli, 2005; Martschuk et al., 2021). Thus, although it is a rule of evidence that judges can disallow misleading and harassing questions (Evidence Act 1995 (NSW) s 41; Evidence Act 2008 (Vic) s 41; Evidence Act 1906 (WA) s 26) this power is rarely invoked. Scholars have suggested that judges are reluctant to intervene due to the culture of the adversarial criminal trial, which includes the provision of autonomy to the parties, and a concern for fairness to the accused (Caruso, 2012; Cossins, 2009; Henning, 2013). Moreover, Henning (2006) contended that using improper questions to undermine the credibility of a witness is a key component of the criminal trial. If the intrinsic structure of the adversarial system discourages intervention, legislative reforms which restrict the scope of cross-examination are unlikely to be enforced if judicial intervention is the sole control (Cossins, 2009). Even when disallowing improper questions is legislated as a duty (e.g., Evidence Act 1995 (NSW) s 41), scholars have opined that this protection is inadequate, due to flexibility in how the legislation can be interpreted, and the admissibility of responses to improper questions that are not prevented (Caruso, 2012; Henning, 2006). Obliging judges not to allow improper questions will not fix a problem intrinsic to the adversarial system and culture (Caruso, 2012). Scholars have suggested a variety of means to remove reliance on judicial intervention, including the appointment of a specialist examiner to cross-examine vulnerable witnesses (Bowden et al., 2014; Cossins, 2020).

In our sample, a number of judges were optimistic that cross-examination had improved over the years. In contrast to these claims, two studies in which transcripts from adult sexual assault trials in the 1950s and 2000s were analysed, demonstrated that similar types of questions (e.g., a high proportion of leading questions) and tactics (e.g., leveraging rape myths) were employed in both time periods (Westera et al., 2017; Zydervelt et al., 2017). Moreover, modern cross-examination was much longer, with $34 \%$ additional questions posed in modern cross-examination compared to the 1950s (Westera et al., 2017). These findings 
conflict with the perspective that cross-examination has improved, and suggest that crossexamination tactics are unlikely to improve in the future in the absence of intervention.

When considering the option of allowing complainants to use pre-recorded interviews as evidence-in-chief, many participants indicated that low quality police interviews would prevent the usefulness of this measure. Participants were particularly concerned about the types of details interviewers elicited, commenting that interviewers often failed to elicit information needed to meet evidential requirements, and focused upon extraneous details which could be leveraged by the defence to discredit the complainant's evidence. Similar concerns have been expressed by prosecutors in previous discussions about interviews of both child (Burrows and Powell, 2014) and adult complainants of sexual offences (Westera and Powell, 2015; Westera et al., 2017). Participants in our sample also emphasized the importance of skilfully conducting interviews with adult complainants of repeated child assault, as their reports were often vague and confused. Indeed, research indicates that witnesses who recall a recurring event often report core information about what typically occurred, and have trouble recalling individual occurrences in detail (Hudson et al., 1992; Woiwod et al., 2019). Yet evidence-based interviewing practices facilitate the retrieval of accurate and detailed reports about a repeated event (see, Brubacher et al., 2014, for a review). Eliciting testimonial evidence through investigative interviews based on these practices is likely to produce higher quality evidence than direct questioning in court, which typically relies upon closed and leading questions (Kebbell et al., 2003). These considerations highlight the necessity of implementing evidence-based training programs for investigative interviewers (see Powell, 2008, for a review).

More needs to be done to protect adult complainants of child sexual assault at trial. The purpose of the criminal justice system is to protect members of the community and their property (Sallman and Willis, 1984). As such the justice system fails if complainants' 
participation leaves them re-traumatised, and leads to the resolve that they would not report sexual assault again (Cossins, 2020; Eastwood and Patton, 2002). Adult complainants of sexual assault should not have to endure questions that are distressing and undermine the reliability of their evidence, and they should be afforded the option of using pre-recorded interviews as their evidence in chief. Although the adversarial legal system is based upon tradition, it is capable of change. In the early 1990s there was opposition to legislative reforms to how children give evidence; today these reforms are widely endorsed (Goodhue, 1991; Westera et al., 2020). 


\section{REFERENCES}

Alaggia R, Collin-Vézina D and Lateef R (2019) Facilitators and barriers to child sexual assault (CSA) disclosures: A research update (2000-2016). Trauma, Violence, \& Assault 20(2): 260-283.

Australian Law Reform Commission, NSW Law Reform Commission and Victorian Law Reform Commission (2005) Uniform evidence law report (ALRC Report 102; NSWLRC Report 112; VLRC Final Report). Report, 5 December. Available at https://www.alrc.gov.au/wp-content/uploads/2019/08/ALRC102.pdf

Bowden P, Henning T and Plater D (2014) Balancing fairness to victims, society and defendants in the cross-examination of vulnerable witnesses: An impossible triangulation? Melbourne University Law Review 37:539-584.

Brubacher SP, Powell MB and Roberts KP (2014) Recommendations for interviewing children about repeated experiences. Psychology, Public Policy, and Law 20:325-225.

Burrows KS and Powell M (2014) Prosecutors' recommendations for improving child witness statements about sexual abuse. Policing and Society 24(2):189-207.

Cashmore J and Shackel R (2013) The long-term effects of child sexual abuse. CFCA Paper No. 11, January 2013. Available at https://aifs.gov.au/cfca/sites/default/files/cfca/ pubs/papers/a143161/cfca11.pdf

Cashmore J and Trimboli L (2005) An evaluation of the NSW child sexual assault specialist jurisdiction pilot. Report for the New South Wales Bureau of Crime Statistics and Research. Legislative Evaluation No 18, January 2005. Available at https://www.bocsar.nsw.gov.au/Publications/Legislative/118.pdf

Caruso D (2012) Proposed reforms for the cross-examination of child witnesses and the reception and treatment of their evidence. Journal of Judicial Administration 21(4): 191-236. 
Cossins, A (2009) Cross-examination in child sexual assault trials: Evidentiary safeguard or an opportunity to confuse? Melbourne University Law Review 22(1): 68-104.

Cossins A (2020) Closing the justice gap for adult and child sexual assault: Rethinking the adversarial trial. London: Palgrave Macmillan.

Cutajar MC, Mullen PE, Ogloff JRP, Thomas SD, Wells DL and Spataro J (2010). Suicide and fatal drug overdose in child sexual abuse victims: A historical cohort study. Medical Journal of Australia 192(4): 184-187

Daly K and Bouhours B (2010) Rape and attrition in the legal process: A comparative analysis of five countries. Crime and Justice 39(1): 565-650.

De Bellis MD and Zisk A.B (2014) The biological effects of childhood trauma. Child and Adolescent Psychiatric Clinics of North America 23(2): 185-222.

Eastwood C and Patton W (2002). The experiences of child complainants of sexual abuse in the criminal justice system. Report for the Criminology Research Council. Available at https://aic.gov.au/publications/tandi/tandi250

Ellison L (1999) The protection of vulnerable witnesses in court: An Anglo-Dutch comparison. International Journal of Evidence and Proof 3(1):29-43.

Feltis BB, Powell MB, Snow PC and Hughes-Scholes CH (2010). An examination of the association between interviewer question type and story-grammar detail in child witness interviews about abuse. Child Abuse \& Neglect 34(6): 407-413.

Fitzgerald J (2006) The attrition of sexual offences from the New South Wales criminal justice system. Crime and Justice Bulletin 92: 1-12.

Goldfarb D, Goodman, GS, Gonzalves, L, Gonzalez A, Wang Y, Wu Y and Vidales D (2020) The accuracy of adults' long-term memory for child sexual abuse. In Miller MK and Bornstein BH (eds) Advances in Psychology and Law: Volume 5. Cham: Springer, pp. $51-82$. 
Goodhue GG (1991) Maryland v. Craig: Balancing sixth amendment confrontation rights with the rights of child witnesses in sexual assault trials. New England Law Review 26:497-528.

Hamlyn B, Phelps A, Turtle J and Sattar G (2004) Are special measures working? Evidence from surveys of vulnerable and intimidated witnesses. Report, Home Office, UK, June 2004.

Henning T (2006) Control of cross-examination - A snowflake's chance in hell? Criminal Law Journal 20(3): 133-137.

Henning T (2013) Obtaining the best evidence from children and witnesses with cognitive impairments - "plus ça change" or prospects new? Criminal Law Journal 37: 155174.

Holt MK, Finkelhor D and Kantor GK (2007). Multiple victimization experiences of urban elementary school students: Associations with psychosocial functioning and academic performance. Child Abuse \& Neglect 31(5): 503-515.

Hong S, Rhee TG and Piescher CN (2018) Longitudinal association of child maltreatment and cognitive functioning: Implications for child development. Child Abuse \& Neglect 84: 64-73.

Horan J and Goodman-Delahunty J (2020) Expert evidence to counteract jury misconceptions about consent in sexual assault cases: Failures and lessons learned. University of New South Wales Law Journal 43(2):707-737.

Hudson JA, Fivush R and Kuebli J (1992) Scripts and episodes: The development of event memory. Applied Cognitive Psychology 6(6): 483-505.

Jaffee SR and Maikovich-Fong AK (2011). Effects of chronic maltreatment and maltreatment timing on children's behavior and cognitive abilities. Journal of Child Psychology and Psychiatry 52(2): 184-194. 
Kebbell M, Deprez S and Wagstaff G (2003) The direct and cross-examination of complainants and defendants in rape trials: A quantitative analysis of question type Psychology, Crime \& Law 9(1):49-59.

Kebbell MR, O'Kelly CM and Gilchrist EL (2007) Rape victims' experiences of giving evidence in english courts: A survey. Psychiatry, Psychology and Law 14(1):111-119.

Kinsella E (2021) I do not recall': The four words that devastated Michelle when she took the witness stand. $A B C$ News, 20 April 2021. Available at https:/www.abc.net.au/news/ 2021-04-21/sexual-assault-complainants-seek-change-to-justice-system/13296644 (Accessed 15 May 2021).

Konradi A (1999) “I Don't Have to be Afraid of You”: Rape Survivors' Emotion Management in Court'. Symbolic Interaction 22: 45-77.

Lamb ME, Brown DA, Hershkowitz I, Orbach Y and Esplin W (2018) Tell me what happened: Questioning children about abuse (2 ${ }^{\text {nd }}$ ed.). Hoboken: Wiley-Blackwell.

Li D, Chu CM and Lai V (2020) A developmental perspective on the relationship between child sexual assault and depression: A systematic and meta-analytic review. Child Assault Review 29(1): 27-47.

Lum JAG, Powell M, Timms L and Snow P (2015) A meta-analysis of cross-sectional studies investigating language in maltreated children. Journal of Speech, Language, and Hearing Research 58(3):961-976. https://doi.org/10.1044/2015_JSLHR-L-140056

Maniglio R (2013) Child sexual abuse in the etiology of anxiety disorders: a systematic review of reviews. Trauma Violence Abuse 14(2): 96-112.

Martschuk N, Powell MB, Goodman-Delahunty J, Thackray S and Westera N (2021) Judicial and lawyer interventions in trials of child sexual abuse. Manuscript submitted for publication. 
McDonald E and Tinsley Y (2011) Use of alternative ways of giving evidence by vulnerable witnesses: Current proposals, issues and challenges. Victoria University of Wellington Law Review 1(1):1-29.

New South Wales Law Reform Commission (2003) Questioning of complainants by unrepresented accused in sexual offence trials. Report No 101, June. Available at https://www.lawreform.justice.nsw.gov.au/Documents/Publications/Reports/Report101.pdf.

New South Wales Law Reform Commission (2020) Consent in relation to sexual offences. Report No 148, September. Available at https://www.lawreform.justice.nsw.gov.au/Documents/Publications/Reports/Report\% 20148.pdf

Victorian Law Reform Commission (2016) The role of victims of crime in the criminal trial process. Report, August. Available at https://www.lawreform.vic.gov.au/publication/ the-role-of-victims-of-crime-in-the-criminal-trial-process-report-2/.

Victorian Law Reform Commission (2004) Sexual Offences: Final Report. Report, July. Available at https://www.lawreform.vic.gov.au/wpcontent/uploads/2021/07/Sexual_Offences_2004_Report_Web.pdf

Powell MB (2008) Designing effective training programs for investigative interviewers of children. Current Issues in Criminal Justice 20(1):189-208.

Quadara A, Nagy V, Higgins D and Siegel N (2015) Conceptualising the prevention of child sexual abuse. Report for the Australian Government Department of Social Services. Final report, 20 June. Available at https://aifs.gov.au/sites/default/files/publicationdocuments/rr33.pdf. 
Queensland Law Reform Commission (2020) Review of consent laws and the excuse of mistake of fact. Report No 78, June. Available at https://www.alrc.gov.au/wpcontent/uploads/2019/08/ALRC102.pdf.

Roebers CM and Schneider W (2000) The impact of misleading questions on eyewitness memory in children and adults. Applied Cognitive Psychology 14(6):509-526.

Royal Commission into Institutional Responses to Child Sexual Abuse (2017) Criminal justice report: Parts VII to X. Available at https://www.childabuseroyalcommission. gov.au/sites/default/files/file-list/final_report__criminal_justice_report_-_parts_vii _to_x_and_appendices.pdf.

Sallmann P and Willis J (1984). Criminal justice in Australia. Melbourne: Oxford University Press.

Shead K (2014) Responding to historical child sexual assault: A prosecution perspective on current challenges and future directions. Current Issues in Criminal Justice 26(1): 5573.

Strauss A and Corbin J (1990) Basics of Qualitative Research: Techniques and procedures for Developing Grounded Theory. Hampshire: Sage Publications Inc.

Valentine T and Maras K (2011) The effect of cross-examination on the accuracy of adult eyewitness testimony Applied Cognitive Psychology 25(4):554-561.

Wolf OT (2017) Stress and memory retrieval: mechanisms and consequences Current Opinion in Behavioral Sciences 14: 40-46.

Westera NJ, Kebbell MR and Milne B (2013) It is better, but does it look better? Prosecutor perceptions of using rape complainant investigative interviews as evidence Psychology, Crime \& Law 19(7):595-610.

Westera NJ and Powell MB (2015) Prosecutors' perceptions of the utility of video-evidence for adult complainants of sexual assault. Criminal Law Journal 39(4): 198-207. 
Westera NJ, Powell MB, Goodman-Delahunty J and Zajac R (2020) Special Measures in child sexual abuse cases: views of Australian criminal justice professionals Current Issues in Criminal Justice 32(2):224-242.

Westera NJ, Powell MB and Milne B (2017) Lost in the detail: Prosecutors' perceptions of the utility of video recorded police interviews as rape complainant evidence Journal of Criminology 50(2):252-268.

Westera NJ, Powell MB, Zajac R and Goodman-Delahunty J (2019) Courtroom questioning of child sexual assault complainants: Views of Australian criminal justice professionals Salus Journal 7(1):20-41.

Westera N, Zydervelt S, Kaladelfos A and Zajac R (2017) Sexual assault complainants on the stand: a historical comparison of courtroom questioning Psychology, Crime \& Law 23(1):15-31.

Woiwod DM, Fitzgerald RJ, Sheahan CL, Price HL and Connolly DA (2019). A metaanalysis of differences in children's reports of single and repeated events Law and Human Behavior 43(1): 99-116.

Zajac R and Cannan P (2009) Cross-examination of sexual assault complainants: A developmental comparison Psychiatry, Psychology and Law 16(1): S36-S54.

Zydervelt S, Zajac R., Kaladelfos A, and Westera N (2017). Lawyers' strategies for cross examining rape complainants: Have we moved beyond the 1950s? British Journal of Criminology 57(3): 551-569. 